\title{
Editorial \\ Contemporary Problems in Combustion-Fuels, Their Valorisation, Emissions, Flexibility and Auxiliary Systems
}

\author{
Tadeáš Ochodek ${ }^{1, *}$, Emmanouil Karampinis ${ }^{2}$ (I) and Artur Pozarlik ${ }^{3}$ \\ 1 Energy Research Center, VŠB-Technical University of Ostrava, 70800 Ostrava, Czech Republic \\ 2 Centre for Research and Technology Hellas, Chemical Process and Energy Resources Institute, \\ 15125 Athens, Greece; karampinis@certh.gr \\ 3 Faculty of Engineering Technology, University of Twente, 7500 AE Enschede, The Netherlands; \\ a.k.pozarlik@utwente.nl \\ * Correspondence: tadeas.ochodek@vsb.cz
}

Citation: Ochodek, T.; Karampinis,

E.; Pozarlik, A. Contemporary

Problems in Combustion-Fuels,

Their Valorisation, Emissions,

Flexibility and Auxiliary Systems.

Energies 2022, 15, 1646. https://

doi.org/10.3390/en15051646

Received: 12 January 2022

Accepted: 9 February 2022

Published: 23 February 2022

Publisher's Note: MDPI stays neutral with regard to jurisdictional claims in published maps and institutional affiliations.

Copyright: (c) 2022 by the authors. Licensee MDPI, Basel, Switzerland. This article is an open access article distributed under the terms and conditions of the Creative Commons Attribution (CC BY) license (https:/ / creativecommons.org/licenses/by/ $4.0 /)$.
This Special Issue is dedicated to the XXIV Symposium on Combustion Processes (23-25 September 2019, Wrocław, Poland), which is an official symposium of the Polish Section of the Combustion Institute that takes place every two years. The XXIV Symposium focused on the following topics:

- Stationary combustion systems at the mega- and nanoscales and their emissionsgeneration, reduction, and problems;

- Advanced combustion technologies and renewable energy sources;

- Diagnostics in combustion systems;

- Fire and detonations, explosions, and supersonic combustion;

- The generation, storage, and utilisation of hydrogen;

- Engines and gas turbines;

- The modelling of combustion processes, including kinetics and industrial applications;

- Other concepts, including assisted combustion (plasmas, electric, and magnetic fields), catalysis, and fuel synthesis;

- The use of by-products of combustion processes;

- The thermal valorisation of solid fuels;

- Zero-emission combustion technologies;

- Industry perspectives on combustion.

The symposium has a long and rich history, and used to be a place of meeting between scientists from both sides of the iron curtain in the 20th century. The papers, presented during the symposium and published as a part of this Special Issue, give an excellent, panoramic view of the present contemporary problems in combustion concerning fuels, emissions, flexibility, and auxiliary systems.

Currently, one of the biggest problems of energy systems nowadays is the need for increased flexibility due to fluctuating supply from intermittent renewable energy sources, such as wind or solar. Therefore, the flexibility of thermal power plants, based on combustion, is currently a subject of intensive investigation. Maczka et al. [1] performed a techno-economic analyses of the use of plasma-assisted combustion in a $200 \mathrm{MW}_{\mathrm{el}}$ power unit. The analysis, performed using net present value (NPV) methodology, showed that using such technology for increasing the flexibility of the boiler could be economically justified, as it allows us to obtain another revenue stream by taking part in the capacity market [1]. Moreover, the study identified the EU limits of $\mathrm{CO}_{2}$ emissions per $\mathrm{kWh}$ of electricity produced for power units that are allowed to participate in capacity markets in member states as one of the key issues preventing the wider implementation of plasmaassisted combustion systems [1]. Nonetheless, the transition of power plants to biomass, e.g., by the implementation of novel valorisation processes, such as torrefaction, could facilitate wider market penetration of the plasma-assisted combustion systems [1]. 
Biomass is an important renewable energy source with significant potential in Europe [2]. Biomass can come from various sources, such as forestry, agriculture, or different types of waste streams, such as sewage sludge [3-5]. Different valorisation routes could be used to improve the fuel properties of low-quality biomass. Luo et al. [6] presented results on the influence of torrefaction and the pelletising of sawdust via gasification in a fixed bed. Torrefaction is a thermal valorisation method, typically performed at temperatures ranging between $250{ }^{\circ} \mathrm{C}$ and $300^{\circ} \mathrm{C}$, with residence time ranging from 30 min up to several hours, either in completely inert or oxygen-deficient atmospheres. Gasification is a process that facilitates the conversion of solid fuels into a combustible mixture of gases, using a ratio of gasification agent (air/oxygen/steam) to fuel that is smaller than the stoichiometric ratio. Such gas is called producer gas, and after further processing, its purified equivalent, called syngas, could be used for the synthesis of various hydrocarbons or the production of hydrogen. Luo et al. [6] observed, for the gasification of torrefied biomass, that CO peak time and volatile release time increased with the increased severity of the torrefaction. Moreover, both CO peak time and volatile release time were lower for pellets in comparison to the loose bed of particles [6].

Sieradzka et al. [7] investigated the pyrolysis of biomass integrated with $\mathrm{CO}_{2}$ capture. Carbon capture can be instrumental in achieving ambitious decarbonisation targets, and has been recognised by the UNFCCC. Therefore, novel solutions are currently being developed, including carbon sequestration using hydrates, membrane-based carbon capture and storage, as well as pre-combustion $\mathrm{CO}_{2}$ capture, or novel cycles [7,8]. Most of the work has been performed so far on post-combustion CCS and the proper integration of CCS with power plants [8]. Pre-combustion $\mathrm{CO}_{2}$ capture seems to be an interesting alternative due to the much smaller volume of gases in comparison to flue gas from combustion. In this context, pyrolysis is a very interesting option, as it could produce different sorts of hydrocarbons, including non-condensable gases, as well as condensable pyrolysis oils. Pyrolysis and Ficsher-Tropsch processes are nowadays the main routes enabling the generation of liquid fuels from biomass. This offers interesting perspectives for using such fuels in gas turbines, either for energy generation or as a fuel in the aviation sector, with the additional importance in terms of energy storage. Sieradzka et al. [7] reported that the in situ use of $\mathrm{CaO}$ during pyrolysis allowed achieving much lower concentrations of $\mathrm{CO}_{2}$, thus improving overall gas quality [7].

Jackowski et al. [9] presented work on the hydrothermal carbonisation (HTC) of brewers' spent grain (BSG). HTC allows valorising biomass at 180 to $260{ }^{\circ} \mathrm{C}$, with increased pressure generated by water vapour and gases generated during the process. Additionally, improvement in terms of properties relevant from the point of view of solid fuels could be observed when hydrochars are compared to raw biomass prior to HTC treatment. This makes HTC a prospective valorisation process for low-quality biomass with relatively high moisture content due to the role of moisture content in combustion [10]. The work of Jackowski et al. [9] confirmed the suitability of HTC for the valorisation of BSG. The study reported that the Weber method for the indirect assessment of HTC process yield is much closer to the direct method, in comparison to the ash tracer method [9], which is a direct consequence of the loss of inorganics by HTC-treated solids [9]. The evidence of that could be seen in the ash yields ranging between 0.8 and 0.5 , depending on the type of BSG and HTC conditions [9]. Improvements in the grindability of carbonised hydrochars also strongly depended on the type of BSG, with a much smaller effect exerted by the severity of the HTC process [9].

The work of Urbanowska et al. [11] focused on the membrane separation of water and organics present in the HTC liquid by-products of the HTC of digestate [11]. HTC is a viable way of valorising digestate, and intensive work is currently focused on the development of installations using HTC as means to recover both carbon and water. However, the treatment of HTC effluent is necessary [11]. Membrane separation gives practical means to remove part of the organics without any chemical reaction, thus keeping the volatile 
fatty acids, which could be digested. Urbanowska et al. [11] reported the COD removal efficiency reaching $30 \%$ using a single, flat ultrafiltration membrane [11].

The research of Hardy et al. [12] was focused on the high-temperature corrosion rates of steam boiler evaporators that use continuous measurements of flue gas composition and neural networks. Boilers in power stations are still the core of energy generation in many countries, and problems related to combustion, such as emissions [13], heat transfer, or corrosion [14], are still subjects of intensive investigation. Hardy et al. [12] reported that measuring $\mathrm{CO}$ and $\mathrm{O}_{2}$ concentrations near the water wall could be effectively supported by neural networks in evaporators' corrosion rate forecasting [12].

Fossil fuels are still an important part of the energy mix nowadays [15,16]. Tic et al. [15] presented their work on the use of modifiers for the combustion of pulverised coal. The combustion of coal with various modifiers, such as $\mathrm{CuSO}_{4} \cdot 2 \mathrm{H}_{2} \mathrm{O}, \mathrm{NaCl}, \mathrm{NH}_{4} \mathrm{Cl}$, $\mathrm{MgSO}_{4} \cdot 7 \mathrm{H}_{2} \mathrm{O}, \mathrm{CaCl}_{2}$, and urea at various concentrations, was investigated within the scope of this study [15]. The modifiers facilitated combustion, increasing the efficiency of the boiler from $65 \%$ to $76 \%$ and allowed the reduction of emissions of $\mathrm{CO}, \mathrm{NO}_{x}$, and $\mathrm{SO}_{2}$ by $9 \%, 12 \%$, and $10 \%$, respectively [15].

Safety is also an important aspect of power generation [17]. Intensive investigation is needed not only for the case of the generation itself but also for the case of energy storage [18]. Jung et al. [18] focused their investigation on the development of an experimental apparatus for the fire resistance testing of batteries, with a primary focus on electric vehicles (xEVs) [18]. The study concluded that the developed rig, consisting of LPG fired Bunsen burners, could be effectively used in the fire resistance testing of various batteries [18].

Kaczorek-Chrobak and Fangrat [19] performed fire properties testing with different types of electrical cables in a standardised large-scale test apparatus. The study concluded that the construction aspects, such as the presence and number of concentric metallic conductors and armour, could form a barrier against flame penetration, thus improving fire properties [19]. Further improvement could be achieved by using materials based on non-plasticised poly(vinyl chloride) [19].

It could be concluded that combustion is intertwined with many other fields, and there are many excellent opportunities for interdisciplinary research stimulated by this field. The great challenge of the decarbonisation of our economy, especially the energy generation sector, requires a holistic approach. The issues have to be carefully looked at from many different vantage points in order to obtain a comprehensive understanding of these complex problems and develop long-term systemic solutions. The discussions performed during the symposium made excellent contributions to the field.

Author Contributions: Conceptualisation: T.O., E.K. and A.P.; writing-original draft preparation: T.O., E.K. and A.P.; writing — review and editing: T.O., E.K. and A.P. All authors have read and agreed to the published version of the manuscript.

Funding: This research received no external funding.

Institutional Review Board Statement: Not applicable.

Informed Consent Statement: Not applicable.

Data Availability Statement: Study does not report any data.

Conflicts of Interest: The authors declare no conflict of interest.

\section{References}

1. Mączka, T.; Pawlak-Kruczek, H.; Niedzwiecki, L.; Ziaja, E.; Chorążyczewski, A. Plasma Assisted Combustion as a Cost-Effective Way for Balancing of Intermittent Sources: Techno-Economic Assessment for $200 \mathrm{MW}_{\mathrm{el}}$ Power Unit. Energies 2020, $13,5056$. [CrossRef]

2. Tzelepi, V.; Zeneli, M.; Kourkoumpas, D.S.; Karampinis, E.; Gypakis, A.; Nikolopoulos, N.; Grammelis, P. Biomass availability in europe as an alternative fuel for full conversion of lignite power plants: A critical review. Energies 2020, 13, 3390. [CrossRef] 
3. Suardi, A.; Latterini, F.; Alfano, V.; Palmieri, N.; Bergonzoli, S.; Karampinis, E.; Kougioumtzis, M.A.; Grammelis, P.; Pari, L. Machine performance and HOG fuel quality evaluation in olive tree pruning harvesting conducted using a towed shredder on flat and hilly fields. Energies 2020, 13, 1713. [CrossRef]

4. Fuller, A.; Maier, J.; Karampinis, E.; Kalivodova, J.; Grammelis, P.; Kakaras, E.; Scheffknecht, G. Fly ash formation and characteristics from (co-)Combustion of an herbaceous biomass and a Greek lignite (Low-Rank Coal) in a pulverized fuel pilot-scale test facility. Energies 2018, 11, 1581. [CrossRef]

5. Seruga, P.; Krzywonos, M.; Seruga, A.; Niedźwiecki, Ł.; Pawlak-Kruczek, H.; Urbanowska, A. Anaerobic Digestion Performance: Separate Collected vs. Mechanical Segregated Organic Fractions of Municipal Solid Waste as Feedstock. Energies 2020, 13, 3768. [CrossRef]

6. Luo, H.; Niedzwiecki, L.; Arora, A.; Mościcki, K.; Pawlak-Kruczek, H.; Krochmalny, K.; Baranowski, M.; Tiwari, M.; Sharma, A.; Sharma, T.; et al. Influence of Torrefaction and Pelletizing of Sawdust on the Design Parameters of a Fixed Bed Gasifier. Energies 2020, 13, 3018. [CrossRef]

7. Sieradzka, M.; Gao, N.; Quan, C.; Mlonka-Mędrala, A.; Magdziarz, A. Biomass thermochemical conversion via pyrolysis with integrated $\mathrm{CO}_{2}$ capture. Energies 2020, 13, 1050. [CrossRef]

8. Ziółkowski, P.; Madejski, P.; Amiri, M.; Kuś, T.; Stasiak, K.; Subramanian, N.; Pawlak-Kruczek, H.; Badur, J.; Niedźwiecki, Ł.; Mikielewicz, D. Thermodynamic Analysis of Negative $\mathrm{CO}_{2}$ Emission Power Plant Using Aspen Plus, Aspen Hysys, and Ebsilon Software. Energies 2021, 14, 6304. [CrossRef]

9. Jackowski, M.; Niedzwiecki, L.; Lech, M.; Wnukowski, M.; Arora, A.; Tkaczuk-Serafin, M.; Baranowski, M.; Krochmalny, K.; Veetil, V.K.; Seruga, P.; et al. HTC of Wet Residues of the Brewing Process: Comprehensive Characterization of Produced Beer, Spent Grain and Valorized Residues. Energies 2020, 13, 2058. [CrossRef]

10. Ryšavý, J.; Horák, J.; Kremer, J.; Hopan, F.; Kuboňová, L.; Krpec, K.; Kubesa, P.; Molchanov, O. Condensation of water vapour in the flue gas path. J. Heat. Vent. Sanit. 2020, 29, 193-199.

11. Urbanowska, A.; Kabsch-Korbutowicz, M.; Wnukowski, M.; Seruga, P.; Baranowski, M.; Pawlak-Kruczek, H.; Serafin-Tkaczuk, M.; Krochmalny, K.; Niedzwiecki, L. Treatment of liquid by-products of hydrothermal carbonization (HTC) of agricultural digestate using membrane separation. Energies 2020, 13, 262. [CrossRef]

12. Hardy, T.; Kakietek, S.; Halawa, K.; Mościcki, K.; Janda, T. Determination of high temperature corrosion rates of steam boiler evaporators using continuous measurements of flue gas composition and neural networks. Energies 2020, 13, 3134. [CrossRef]

13. Avagianos, I.; Vounatsos, P.; Papandreou, I.; Maier, J.; Grammelis, P.; Kakaras, E. Nanoparticle Emission and Characterization from Pre-Dried Lignite and Bituminous Coal Co-Combustion. Energies 2020, 13, 2373. [CrossRef]

14. Hardy, T.; Arora, A.; Pawlak-Kruczek, H.; Rafajłowicz, W.; Wietrzych, J.; Niedźwiecki, Ł.; Vishwajeet; Mościcki, K. NonDestructive Diagnostic Methods for Fire-Side Corrosion Risk Assessment of Industrial Scale Boilers, Burning Low Quality Solid Biofuels-A Mini Review. Energies 2021, 14, 7132. [CrossRef]

15. Tic, W.J.; Guziałowska-Tic, J. The effect of modifiers and method of application on fine-coal combustion. Energies $2019,12,4572$. [CrossRef]

16. Pawlak-Kruczek, H.; Czerep, M.; Niedzwiecki, L.; Karampinis, E.; Violidakis, I.; Avagianos, I.; Grammelis, P. Drying of Lignite of Various Origins in a Pilot Scale Toroidal Fluidized Bed Dryer using Low Quality Heat. Energies 2019, 12, 1191. [CrossRef]

17. Skřínský, J.; Ochodek, T. Explosion characteristics of propanol isomer-air mixtures. Energies 2019, 12, 1574. [CrossRef]

18. Jung, H.; Moon, B.; Lee, G.G. Development of experimental apparatus for fire resistance test of rechargeable energy storage system in XEV. Energies 2020, 13, 465. [CrossRef]

19. Kaczorek-Chrobak, K.; Fangrat, J. Influence of constructional-material parameters on the fire properties of electric cables. Energies 2019, 12, 4569. [CrossRef] 